\section{Precision prevention: time to move beyond universal interventions}

\author{
Flaura K Winston, ${ }^{1,2,3}$ Kristina Puzino, ${ }^{4}$ Daniel Romer ${ }^{5}$
}

Nearly two decades ago, the Institute of Medicine (IOM) in the USA recognised that many adverse health outcomes result from behavioural tendencies that place individuals at risk. Programmes designed to change these behaviours could have long-term salutary effects. They further noted the heterogeneity within and across populations and over time in the nature and severity of unhealthy behaviours. To address the disparate needs of individuals in a population, the IOM proposed a multi-tiered framework for prevention that provides differential and increasingly more intense preventive intervention as a function of level of risk and response to prior intervention. ${ }^{1}$ This framework has been adopted for a wide range of educational and behavioural health issues; for example, in the school setting, the prevention and early intervention for preschool children at risk for learning or behaviour problems; ${ }^{2} 3$ in the community setting, the management of blood pressure ${ }^{4}$ and in the inpatient clinical setting, the secondary prevention of traumatic stress. ${ }^{5}$ However, unintentional injury prevention still relies largely on 'one-size-fits-all' or universal strategies (eg, laws and their enforcement and education campaigns). While such 'universal' injury prevention strategies can reach the widest audience, complementary targeted risk approaches are necessary to meet the needs of minority, higher risk populations, and to increase the value of prevention strategies.

Injury prevention recognises the concept of 'tailored interventions' that deliver culturally sensitive or other adapted measures depending upon the characteristics of the target audience. These include altering the language in which an intervention is delivered ${ }^{6}$ to a

\footnotetext{
${ }^{1}$ Center for Injury Research and Prevention, The Children's Hospital of Philadelphia, Philadelphia, Pennsylvania, USA; ${ }^{2}$ Department of Pediatrics, Perelman School of Medicine, Philadelphia, Pennsylvania, USA; ${ }^{3}$ Leonard Davis Institute for Health Economics, Philadelphia, Pennsylvania, USA; ${ }^{4}$ Lehigh University, Bethlehem, Pennsylvania, USA; ${ }^{5}$ Annenberg Public Policy Center, University of Pennsylvania, Philadelphia, Pennsylvania, USA

Correspondence to Dr Flaura K Winston, The Center for Injury Research and Prevention, The Children's Hospital of Philadelphia, 3535 Market Street, Suite 1150, Philadelphia, PA 19104, USA; flaura@upenn.edu
}

population or varying the implementation of an intervention to accommodate important individual differences, for example, through kiosk-delivered tailored messaging ${ }^{7}$ or safety technology tailored to the characteristics of the vehicle occupant. When air bags were first introduced, they were largely one-size-fits-all and children and short-statured women suffered fatal injuries when in the path of the deploying air bag. 9 ' Over the past few decades, manufacturers of vehicles, restraints and air bags have increasingly added sophisticated sensors that recognise the presence of small-statured occupants who are seated close to the air bag, putting them at risk. By adding sophisticated algorithms for air bag deployment (suppression, tethering, etc), they have achieved a significant reduction in air bag-induced injuries. ${ }^{10}$

The IOM framework, however, goes beyond the tailoring of interventions to support achievement of low risk, safe behaviors and good health outcomes, recognising that individuals within a target population possess differing needs. The so-called 'tiered risk strategies' deliver a more dynamic and personalised approach whereby, when needed, members of the target audience may get more intensive interventions (eg, with multiple components, supports and modalities) based on their level of risk. Interventions are organised into tiers of increasing intensity to match increasing levels of individual risk. Three tiers have been distinguished: universal interventions, delivered to wide populations to meet the risks typically possessed by the target population. These include interventions that may be tailored to individual subpopulations, such as in our air bag example, which have been optimised to meet the needs of a range of occupants. However, a second tier, selected interventions, may be required to build on universal interventions at added intensity and complexity to meet the needs of those recognised to have higher levels or different risks from those typical of the population but who have not yet displayed unsafe or unhealthy behaviors or experienced negative health or safety outcomes. Finally, there may be a need for a third tier, indicated interventions, which meet the needs of those who have already exhibited adverse outcomes and require yet more resources and individual tailoring.

Reviews of youth violence prevention interventions have shown that programmes aimed at the selected and indicated levels produce the strongest effects. ${ }^{11} 12$ This is not to discourage universal approaches, but experience with this very difficult prevention problem demonstrates that tiered approaches are able to significantly enhance programme outcomes for those most in need of more intensive intervention. One current implementation of a tiered risk programme is the Violence Prevention Initiative at The Children's Hospital of Philadelphia. ${ }^{13}$ At the universal level, efforts are focused on community and school bullying prevention programming. Selective interventions identify children at risk for violence due to their exposure to intimate partner violence in their homes and connect families with community support services through the Emergency Department and Primary Care practices. The most intensive, indicated efforts deliver direct support services to child and adolescent victims of interpersonal violence.

Unintentional injury prevention efforts are beginning to recognise that individuals with medical conditions (or other risk factors) may need more intensive programmes to prevent injury. For example, while universal fall prevention targets older adults in the community setting, ${ }^{14}$ more intensive programmes target those who have suffered from stroke ${ }^{15}$ or dementia. ${ }^{16}$ Similarly, while the American Academy of Paediatrics advocates for anticipatory guidance regarding injury prevention, tailored to age and developmental level, ${ }^{17}$ increased awareness that children with disabilities have a higher injury risk has led to more intensive and individualised efforts. ${ }^{18}$ Best practice stipulates creating accessible and safe school environments and playgrounds to accommodate the needs of special needs children $^{19}$ and intensive educational efforts for parents, teachers and the children themselves on how to safely move through their environments.

To further illustrate the application of tiered risk to injury prevention, an approach is presented for developing a comprehensive approach for a target population: young, novice drivers.

Motor Vehicle Crashes (MVCs), particularly those involving young, novice drivers, are the leading cause of death to adolescents in the USA and other developed countries. $^{20}$ The observation that 
young driver crash risk peaks with the transition from adult-supervised practice (during the learner phase) to unsupervised driving (during the restricted or provisional license phase $)^{21-24}$ underscores the importance of managing the safe transition to independent driving.

Gradual improvement in driving skill occurs as driving experience increases. ${ }^{25}$ However, situational factors can mitigate or exacerbate traits that predispose to risky driving (eg, attention deficit hyperactivity disorder (ADHD)), whereby improvements might be achieved through daily medication management of ADHD symptoms and/or behavioural interventions implemented at home or in school. However, risk could increase in the face of inadequate sleep or poor driving conditions. Momentary changes will also occur due to the presence of distractions inside or outside the vehicle. Our recent review of research regarding the development of attention skills in adolescents finds that these skills vary considerably within as well as between ages. ${ }^{26}$ Some adolescents at age 15 have adequate attention skills for driving, while others may not. In addition, some youth exhibit risky driving habits, while others do not. Strategies for addressing such differences in risk will be necessary for comprehensive prevention strategies to be beneficial.

\section{UNIVERSAL LEVEL INTERVENTIONS: A GOOD FOUNDATION, BUT MORE IS NEEDED}

Unfortunately, young driver crash prevention and safe driving promotion still largely rely on a 'one-size-fits-all' strategy — primarily "Graduated Driver Licensing" (GDL) provisions-that set requirements and time milestones for increasing driving privileges for young drivers. ${ }^{27} 28$ Characteristics of adolescents, their families and the broader ecology that put them at population-level risk (appropriate for universal GDL alone) must be differentiated from characteristics that put individuals within the population at increased risk (requiring selected or indicated interventions). GDL is an example of a universal level intervention that is an important foundational component of a tiered-risk framework but insufficient for a comprehensive approach to young driver safety. Laws, like GDL, are directed at changing the norm and providing a minimal level for expectations around motor vehicle safety, influencing the attitudes and behaviours of the population as a whole, without regard to individual risk. However, those in the field recognise that novice drivers are a diverse group according to risk and that this risk is time dependent and sensitive to circumstances. $^{29} 30$

The provisions in GDL were developed in response to epidemiological studies documenting the elevated crash risk for the average novice driver, without regard to individual differences in risk outcomes. These provisions for existing driving laws were initially developed to increase driver learning but ultimately proved beneficial in reducing crashes by limiting young driver exposure to higher risk driving conditions during early novice driving. ${ }^{31}$ GDL provisions stage increases in driving privileges in response to the anticipated gradual improvements in driving ability expected with experience, as well as advances in maturity that lead to sound judgments and ability to manage peer passengers. $^{32}$ Although applications of GDL vary by state or country, the learner and accompanied driver phases of most GDL provisions allow new drivers to gain driving experience only in the presence of an adult passenger. The provisional or restricted license phase restricts newly licensed drivers to lower risk conditions for a period of time after licensure. A growing number of evidence-based, evaluated universal interventions are becoming available to supplement GDL through enhanced driver training, supervised practice driving and postlicensure restrictions of novice drivers (training: see work by Fisher et $a l^{33}$ and Isler and Isler; ${ }^{34}$ supervised practice: see Mirman et $a l,{ }^{35}$ postlicensure restrictions: see Zakrajsek et $a l^{36}$ ).

Various characteristics of the young driver, his or her family and community, such as realistic risk perception, ${ }^{37}$ authoritative and responsive parenting ${ }^{38-41}$ and a strong GDL programme in the state in which the family resides, ${ }^{42}$ place a teen at a typical level of crash risk, where a universal level intervention strategy is likely appropriate. A key challenge to a risk management strategy for young drivers is the recognition that individual driving risk can vary dramatically depending on stable characteristics of the driver (traits) and the situations (states) that the driver faces; therefore, so, too should the prevention strategy. (For more on the Winston-Romer Trait-State Model of driving risk applied to young driver inattention, see the recent summary.) ${ }^{26}$ Thus, for teens with above average levels of risk, more intense strategies could help to build skills or limit situations that increase the propensity to have poor driving performance or to engage in risky or unsafe driving behaviours.

\section{SELECTED LEVEL INTERVENTIONS: MEETING THE NEEDS OF THOSE AT INCREASED RISK}

To begin to build out the more comprehensive strategy, those young drivers with more than the 'average' propensity for risk need to be identified, and selected level interventions need to be developed and delivered to meet their needs. The literature reveals risk factors at the biopsychological, family and community level that put a teen at increased risk for crashing. At the biopsychological level, the presence of atypical development, which may contribute to problems with attention "deployment" and behavioural and emotional regulation, can increase a young driver's risk of receiving traffic citations and crashing. ${ }^{43}$ At the family level, permissive or uninvolved parents or a family history of moving citations or at-fault collisions increase a young driver's risk for unsafe behaviours and crashing. ${ }^{38} 44$

At the community level, the absence of strong GDL provisions where the family resides also increases risk. While strengthening GDL is the best strategy at the universal level, political conditions may preclude such enhancements putting young drivers at risk. In such locales, young drivers and their families would likely benefit from a selected level, more intensive intervention that includes education and support to fill the gap related to weak laws. One new programme developed by Fabiano et $a l^{45}$ addresses adolescents with ADHD and their parents. This intervention combines in-vehicle monitoring and cognitive-behavioural therapy, including communication and negotiation training, goal-setting and contingency contracting. Other strategies involve optimising medication for ADHD, including the use of extended release formulations to ensure that ADHD symptoms are managed through the evening and other high-risk situations. ${ }^{46}$ A recent systematic review highlighted an urgent need for the evaluation of behavioural interventions for young drivers with ADHD. ${ }^{47}$

Identification of those at increased risk could occur at a routine physician visit, when completing a medical certification for driving (where required) ${ }^{48}$ or through self-identification by the young driver or his or her parent. Insurance companies or motor vehicle departments could identify and refer risky families for selective interventions. Of course, proven interventions and delivery mechanisms would need to 
be developed to which young drivers and their families could be referred.

\section{INDICATED LEVEL INTERVENTIONS: FOCUSING ON THOSE AT HIGHEST RISK}

Drivers who display potentially dangerous driving behaviours, especially those who do not follow driving laws, pose the highest safety risks and require added attention. ${ }^{24} 4950$ An Australian study found that if a novice driver received a first arrest for driving under the influence (DUI) in conjunction with a crash, he/she was significantly more likely than other novice drivers for future DUIs and crashes $^{51}$ and a US study demonstrated that young drivers cited for distracted driving had a 6.6-fold increased crash risk (RR 6.6, 95\% CI 5.9 to 7.4). ${ }^{52}$ In addition, young drivers are at increased risk when in families for whom previous interventions were not implemented or not effective (eg, parents cannot provide adequate supervision and monitoring or parents or teens are very high risk drivers. For these cases, closer support through an indicated level intervention strategy could be appropriate. It is likely that interventions will differ depending on the degree of parental involvement exhibited. For some families, use of and training on invehicle monitoring technology may enhance the ability of parents to monitor their adolescent's driving. For other families, yet more intensive intervention by professionals may be required that includes monitoring technology and training on feedback techniques. For the highest risk young drivers and their families, closer supervision by non-parent, safe driver adults and/or law enforcement may be required.

McGehee $e t a l^{53}$ at the University of Iowa were among the first to pioneer technological interventions to enhance parental monitoring of young drivers for driving risk using an event-triggered video device placed in the car and detailed feedback to parents in the form of a graphic report card and video clips of at-risk driving behaviours. The programme's evaluation demonstrated a reduction in video-captured safety events among young drivers in the intervention group when compared with those in the control group. While the study did not recruit for at-risk youth, some in the study displayed high-risk driving that was responsive to the intervention.

Another robust programme was started in Israel, and components of this intervention have been now incorporated into a European trial to investigate the benefit of technology in enhancing parental monitoring. Various levels of feedback (eg, in-vehicle display, text messaging to parents and a website) were evaluated in a multi-arm randomised controlled trial, again with typical rather than at-risk families, with early indications of acceptability and short-term reductions in crash rates and driving risk indices. ${ }^{54}$

Recognising that monitoring interventions require the diligence and coaching/ feedback skill of the parent/adult monitor, recent enhancements to in-vehicle monitoring programmes have incorporated professional support. For example, the Iowa team incorporated motivational interviewing strategies to address the issue that some families need assistance in how to best provide feedback to their young drivers (McGehee DV, personal communication, 26 September 2013), ${ }^{55}$ an element that could become part of both selective and indicated interventions. The Israeli team incorporated a professional coaching component to train parents to match their vigilance to the degree of risky driving behaviour captured by the technology. ${ }^{56} 57$ This 'tiered risk' approach was found most useful among young drivers who exhibited more risky behaviour.

To achieve good outcomes for these high-risk young drivers, particularly those in families with parents who are uninterested or incapable of monitoring/coaching their adolescent, professional support (from a physician, psychologist, educator and/or driving trainer/evaluator) will likely be needed to assess the adolescent's driving competence, traits and states that degrade driving performance and to create and implement a driver training and management plan. Interventions that have succeeded in helping parents to develop better monitoring skills may also be appropriate for such cases ( eg, work by Dishion and colleagues $^{58}$ using the Family Check-Up programme). An urgent need for intervention content exists to correct problem driving behaviours as most interventions do not involve families but rather focus on 're-education' of the individual and have had limited success. ${ }^{59} 60$ For some of the hardest of cases, the possibility would have to be considered to require alternate adult supervision/monitoring, monitoring by law enforcement or insurers and/or restriction or suspension of a teen's driving license.

\section{CONCLUSIONS AND FUTURE AGENDA FOR RESEARCH, PROGRAMMES AND POLICY}

Young, novice drivers demonstrate variability for crash and injury risk within the population and within the individual over time, necessitating a move towards a multi-level prevention framework to fit the right strategy to the right individual at the right time and in the right context. Just as each adolescent is unique so too is each adolescent driver. The current state of knowledge points to the importance of GDL and parent involvement, as well as the need to move one step further by incorporating a more robust understanding of the parent and young driver, their relationship with each other, and the broader context in which this relationship exists. More work is needed to understand how to reduce risk and promote protective factors for a specific adolescent at a specific developmental stage with individual characteristics (eg, medical, psychological, social and environmental factors). ${ }^{1}$ Therefore, research is needed to develop interventions that can be placed within a tiered clinical and public health prevention strategy to reduce young driver risk (universal, selected and indicated level interventions) that (1) match the intensity of intervention to the risk level of the target population and (2) match effective interventions to specific risks and problem behaviours.

Based on strong evidence from evaluations of tiered risk strategies for mental and physical health promotion, there is reason for substantial hope that the successes that have been achieved in injury prevention can be extended to those at highest risk. Just as precision medicine aims to tailor medical therapy to the needs of the individual, precision injury prevention should provide comprehensive strategies that aim to meet the needs of all individuals within a population in achieving low-risk outcomes over time. This commentary highlighted the application of a tiered-risk approach to addressing the needs of individual higher risk young drivers and their families. However, the urgent need for interventions to meet the prevention needs of individuals in populations across all injury mechanisms should serve as a 'road map' guiding future research needs to fill gaps.

Acknowledgements The authors would like to acknowledge the Center for Injury Research and Prevention for its support. The findings and conclusions are those of the author(s) and do not necessarily represent the views of the Pennsylvania Department of Transportation (Penn DOT).

Funding This paper was written with partial support from a grant from the Pennsylvania Department of Transportation (Penn DOT) CTSP-2015-CHOP-00026.

Competing interests None declared. 
Provenance and peer review Not commissioned; externally peer reviewed.

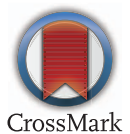

To cite Winston FK, Puzino K, Romer D. Inj Prev 2016;22:87-91.

Published Online First 13 August 2015

Inj Prev 2016;22:87-91.

doi:10.1136/injuryprev-2015-041691

\section{REFERENCES}

1 National Research Council, Institute of Medicine, \& Transportation Research Board. Preventing teen motor crashes: contributions from the behavioral and social sciences. Washington DC: National Academy Press, 2007.

2 Doll B, Pfohl W, Yoon JS. Handbook of youth prevention science. New York: Routledge, 2010.

3 Donnelly Peter D, Catherine L, Ward, eds. Oxford textbook of violence prevention: epidemiology, evidence, and policy. Oxford University Press, 2014:169-177.

4 Thomas KL, Bimal RS, Elliot-Bynum S, et al. Check it, change it: a community-based, multifaceted intervention to improve blood pressure control. Circ Cardiovasc Qual Outcomes 2014;7:828-34.

5 Kazak AE, Kassam-Adams N, Schneider S, et al. An integrative model of pediatric medical traumatic stress. J Pediatr Psychol 2006;31:343-55.

6 Erkoboni D, Ozanne-Smith J, Rouxiang C, et al. Cultural translation: acceptability and efficacy of a US-based injury prevention intervention in China. Inj Prev 2010;16:296-301.

7 van Beelen MEJ, Beirens TMJ, den Hertog P, et al. Effectiveness of web-based tailored advice on parents' child safety behaviors: randomized controlled trial. J Med Internet Res 2014;16:e17.

8 Shields W, McDonald E, McKenzie L, et al. Utilizing the pediatric emergency department to deliver tailored safety messages: results of a randomized controlled trial. Pediatr Emerg Care 2013;29:628.

9 Winston FK, Reed R. Air bags and children: results of a National Highway Traffic Safety Administration special investigation into actual crashes. (No. 962438). Detroit: Society of Automotive Engineers Technical Paper, 1996.

10 Arbogast KB, Durbin DR, Kallan MJ, et al. Injury risk to restrained children exposed to deployed first-and second-generation air bags in frontal crashes. Arch Pediatr Adolesc Med 2005;159:342-6.

11 Limbos MA, Chan LS, Warf C, et al. Effectiveness of interventions to prevent youth violence: a systematic review. Am J Prev Med 2007;33:65-74.

12 Matjasko JL, Vivolo-Kanto AM, Massetti GM, et al. A systematic meta-review of evaluations of youth violence prevention programs: common and divergent findings from 25 years of meta-analyses and systematic reviews. Aggression Violent Behav 2012;17:540-52.

13 The Children's Hospital of Philadelphia, Center for Injury Research and Prevention. Violence Prevention Initiative. https://injury.research.chop.edu/ violence-prevention-initiative\#.VYLeCxw2sro (retrieved 18 Jun 2015).

14 Gates S, Fisher JD, Cooke MW, et al. Multifactorial assessment and targeted intervention for preventing falls and injuries among older people in community and emergency care settings: systematic review and meta-analysis. BMJ 2008;336:130-3.

15 Batchelor FA, Mackintosh SF, Said CM, et al. Falls after stroke. Int J Stroke 2012;7:482-90.
16 Zafar SN, Cornwell EE III, Greene WR. Geriatric trauma and injury prevention. In: Geriatric trauma and critical care. Edited by Yelon, JA and Luchette, FA New York: Springer, 2014:221-224.

17 Bright Futures, Bright Futures Guidelines and Pocket Guide. https://brightfutures.aap.org/materials-andtools/guidelines-and-pocket-guide/Pages/default.aspx (retrieved 18 Jun 2015).

18 Ramirez M, Peek-Asa C, Kraus JF. Disability and risk of school related injury. Inj Prev 2004;10:21-6.

19 United States Consumer Product Safety Commission, Playground Safety. http://www.cpsc.gov/en/ Safety-Education/Safety-Guides/Sports-Fitness-andRecreation/Playground-Safety/ (retrieved 18 Jun 2015).

20 Centers for Disease Control and Prevention. (2011, 4 March 2010). Web-based Injury Statistics Query and Reporting System (WISQARS).http://www.cdc.gov/ injury/wisqars/index.html (retrieved 13 Jun 2011)

21 Lewis-Evans B. Crash involvement during the different phases of the New Zealand Graduated Driver Licensing System (GDLS). I Safety Res 2010;41:359-65

22 Masten SV, Foss RD. Long-term effect of the North Carolina Graduated Driver Licensing system on licensed driver crash incidence: a 5-year survival analysis. Accid Anal Prev 2010;42:1647-52.

23 Mayhew DR, Simpson HM, Desmond K, et al. Specific and long-term effects of Nova Scotia's Graduated Licensing Program. Traffic Inj Prev 2003;4:91-7.

24 McCartt AT, Shabanova VI, Leaf WA. Driving experience, crashes and traffic citations of teenage beginning drivers. Accid Anal Prev 2003;35:311-20.

25 Curry AE, Pfeiffer MR, Durbin DR, et al. Young Driver Crash Rates in New Jersey by Driving Experience, Age, and License Phase. 2014. https://www. aaafoundation.org/sites/default/files/OlderVsYounger NovicesNJ-FINAL\%20FTS\%20Format.pdf (retrieved 13 Jun 2011).

26 Romer D, Lee YC, McDonald CC, et al. Adolescence, attention allocation, and driving safety. J Adolesc Health 2014;54:S6-S15.

27 McKnight AJ, Peck RC. Graduated Driver Licensing and safer driving. J Safety Res 2003;34:85-9.

28 Williams AF, Shults RA. Graduated Driver Licensing research, 2007-present: a review and commentary. J Safety Res 2010;41:77-84.

29 Scott-Parker B, Watson B, King MJ, et al. The influence of sensitivity to reward and punishment, propensity for sensation seeking, depression, and anxiety on the risky behaviour of novice drivers: a path model. Br J Psychol 2012;103:248-67.

30 Guo F, Simons-Morton BG, Klauer SE, et al. Variability in crash and near-crash risk among novice teenage drivers: a naturalistic study. J Pediatr 2013;163:1670-6.

31 McKnight AJ, Peck RC. Graduated driver licensing: what works? Inj Prev 2002;8:32-6.

32 Zhu M, Cummings $\mathrm{P}$, Chu $\mathrm{H}$, et al. Graduated driver licensing and motor vehicle crashes involving teenage drivers: an exploratory age-stratified meta-analysis. Inj Prev 2013;19:49-57.

33 Fisher DL, Pollatsek AP, Pradhan A. Can novice drivers be trained to scan for information that will reduce their likelihood of a crash? Inj Prev 2006;12 (Suppl 1):25-9.

34 Isler RB, Isler N. Online training in situation awareness, hazard perception and risk management for drivers in New Zealand. In: Australasian Road Safety Research, Policing and Education Conference 2011; 2011:1-8.

35 Mirman JH, Curry AE, Winston FK, et al. Effect of the Teen Driving Plan on the driving performance of teenagers before licensure: a randomized clinical trial. JAMA Pediatr 2014;168:764-71.

36 Zakrajsek JS, Shope JT, Greenspan Al, et al. Effectiveness of a brief parent-directed teen driver safety intervention (Checkpoints) delivered by driver education instructors. J Adolesc Health 2013;53: 27-33.

37 Cestac J, Paran F, Delhomme P. Young drivers' sensation seeking, subjective norms, and perceived behavioral control and their roles in predicting speeding intention: how risk-taking motivations evolve with gender and driving experience. Saf Sci 2011;49:424-32.

38 Ginsburg KR, Durbin DR, García-España J, et al. Associations between parenting styles and teen driving, safety-related behaviors and attitudes. Pediatrics 2009;124:1040-51.

39 Hartos J, Eitel P, Simons-Morton B. Parenting practices and adolescent risky driving: a three-month prospective study. Health Educ Behav 2002;29: 194-206.

40 Hartos JL, Eitel P, Haynie DL, et al. Can I take the car? Relations among parenting practices and adolescent problem-driving practices. J Adolesc Res 2000; 15:352-67.

41 Mirman JH, Albert D, Jacobsohn LS, et al. Factors associated with adolescents' propensity to drive with multiple passengers and to engage in risky driving behaviors. J Adolesc Health 2012;50:634-40.

42 Curry AE, Pfeiffer MR, Localio R, et al. Graduated driver licensing decal law: effect on young probationary drivers. Am J Prev Med 2013;44:1-7.

43 Jerome L, Segal A, Habinski L. What we know about ADHD and driving risk: a literature review, meta-analysis and critique. J Can Acad Child Adolesc Psychiatry 2006;15:105-25.

44 Wilson RJ, Meckle W, Wiggins S, et al. Young driver risk in relation to parents' retrospective driving record. J Safety Res 2006;37:325-32.

45 Fabiano GA, Hulme K, Linke $S$, et al. The Supporting a Teen's Effective Entry to the Roadway (STEER) program: feasibility and preliminary support for a psychosocial intervention for teenage drivers with ADHD. Cogn Behav Pract 2011;18:267-80.

46 Barkley RA, Cox D. A review of driving risks and impairments associated with attention-deficit/ hyperactivity disorder and the effects of stimulant medication on driving performance. J Safety Res 2007;38:113-28.

47 Bruce C, Unsworth C, Tay R. A systematic review of the effectiveness of behavioural interventions for improving driving outcomes in novice drivers with attention deficit hyperactivity disorder (ADHD). $\mathrm{Br} J$ Occup Ther 2014;77:348-57.

48 Non-commercial learner's permit application. http:// www.dmv.state.pa.us/pdotforms/dl_forms/dl-180.pdf (retrieved 13 Jun 2011).

49 Vernick JS, Li G, Ogaitis S, et al. Effects of high school driver education on motor vehicle crashes, violations, and licensure. Am J Prev Med 1999;16:40-6.

50 Carnegie JA, Strawderman WE and Li W. Study of recidivism rates among drivers administratively sanctioned by the New Jersey motor vehicle commission. New Brunswick, NJ: Rutgers, The State University of New Jersey, 2009:1-66.

51 Ferrante AM, Rosman DL, Marom Y. Novice drink drivers, recidivism and crash involvement. Accid Anal Prev 2001;33:221-7.

52 Blanar L, Kaufman R, Freedheim A, et al. Crash risk associated with distracted driving citations among young drivers (abstract). Pediatric Academy Society Meeting; 2015. http://www.abstracts2view.com/pas/ view.php?nu=PAS15L1_2175.1

53 McGehee DV, Raby M, Carney C, et al. Extending parental mentoring using an event-triggered video intervention in rural teen drivers. J Safety Res 2007:38:215-27.

54 Toledo T, Musicant O, Lotan T. In-vehicle data recorders for monitoring and feedback on drivers' behavior. Transportation Res Part C: Emerg Technol 2008;16:320-31.

55 Peek-Asa C, Cavanaugh JE, Yang J, et al. Steering teens safe: a randomized trial of a parent-based 
intervention to improve safe teen driving. BMC Public Health 2014;14:777.

56 Farah $\mathrm{H}$, Musicant $\mathrm{O}$, Shimshoni $\mathrm{Y}$, et al. The first year of driving-can IVDR and parental involvement make it safer? Paper presented at the Transportation Research Board 92nd Annual Meeting. Washington DC 2013.

57 Lotan T, Albert G, Ben-Bassat T, et al. Potential benefits of in-vehicle systems for understanding driver behaviour; A series of small-scale Naturalistic Driving studies in Israel. Prologue Deliverable D3.2. Or Yarok, Hod Hasharon, Israel: 2010:145.

58 Van Ryzin MJ, Dishion TJ. The impact of family-centered intervention on the ecology of adolescent antisocial behavior: modeling developmental sequelae and trajectories during adolescence. Dev Psychopathol 2012;24:1139-55.
59 af Wåhlberg AE. Re-education of young driving offenders: effects on self-reports of driver behavior. J Safety Res 2010;41:331-8.

60 Masten SV, Peck RC. Problem driver remediation: a meta-analysis of the driver improvement literature. J Safety Res 2004;35:403.

\section{Increasing injury rates}

Most readers believe that the injury picture has improved worldwide over recent years. But a recent study in the USA found a 38\% increase from 2010 to 2014 in San Antonio, Texas. This may be a signal that other areas are similarly affected. The increase was mainly due to falls, machinery and crashes. The falls may be due to an ageing population and the machinery increase may reflect the economic upturn in the region but there was no obvious explanation for the rise in crash injuries.

\section{Plaintiff negligent in suit over defective motorcycle helmet}

In a civil suit in the USA the plaintiff argued a motorcycle helmet was not equipped with 'critical injury prevention technology'. However, the jury assigned all the negligence to the plaintiff who had been injured in a motorcycle crash. His helmet was not judged to be defective when it was sold. Instead the plaintiff was fully negligent in causing the injury but there is no explanation given to explain their reason for doing so.

\section{More injuries from airplane turbulence}

Extreme turbulence may be increasing and airlines need improved technologies to detect it. Some believe climate change is partly responsible for the increase. One scientist predicts 'the average strength of trans-Atlantic turbulence at cruising altitudes could increase by between $10 \%$ and $40 \%{ }^{\prime}$. A consortium in Europe is using a laser to detect patterns of turbulence, allowing time to change course. Airlines urge passengers to obey seat belt signs.

\section{Children's Injury Prevention Center celebrates 25th birthday}

The Connecticut Children's Injury Prevention Center has worked to reduce unintentional injury for 25 years. It is a model for other such programmes. A report in this journal describes the core of its successful approach: identifying injury patterns, implementing innovative solutions, advocating for effective community-based programmes and policies; education and training; community outreach; and public policy advocacy, for example, helmet laws, passenger safety, graduated driver's licensing and seat belt use. 